\title{
Ancient Patterns of the Sporting Body ${ }^{1}$
}

\author{
Jakub Mosz
}

Josef Pilsudski University of Physical Education in Warsaw, Poland

ABSTRACT

\begin{abstract}
In the world of ancient culture you can find images of corporeality which may be recognised as patterns of the sporting body. They come from Greek sculpture and vase painting. Among the preserved Greek cultural artefacts there can be pointed out three examples of patterns of male corporeality and one example of female corporeality connected with the world of sport. These are Polyclitus's sculptures "Doryphorus" and "Diadoumenos", Myron's sculpture "Discus Thrower", Lysippus's sculpture of "Heracles Farnese" and painting presenting Atalanta. They constitute ancient patterns of the sporting body, which are recognisable in the world of the European culture from the age of Renaissance to the $20^{\text {th }}$ century. Each of those cultural artefacts points out to separate aspects of the world of sport: Polyclitus's sculptures are pictures of beauty of the body, Myron's sculpture expresses sporting movement, Lysippus's sculpture symbolises power and the figure of Atalanta is the first gender pattern in the world of sport. Ancient patterns of the sporting body perform functions of cultural archetypes in the contemporary world of sport. The contemporary sporting body is a corporeal form which is perceived and interpreted through the prism of the symbolic layer of ancient images of corporeal forms. A part of those corporeal patters has lost in European culture their sporting references, which were visible for Greek civilization. It refers to Polyclitus's sculptures and the figure of Atalanta, which was provided by Renaissance and Baroque art with a different semantic context. Research into cultural aspects of sport requires reconstruction of their sporting genealogy making it possible to construct wider interpretative contexts of contemporary corporeality. The notion of the "archetype of the sporting body" in European culture is enriched with a differentiated objective layer, which is composed of ancient patters of the sporting body encountered in social consciousness of the world of European art. sport body, cultural patterns, ancient Greece
\end{abstract}

KEYWORDS

Contemporary sport reflects diversity of forms of the human body. That diversity is connected with a great diversity of forms of sports competition.

The subject of our considerations is the image of the body, its external layer and sport body patterns, and that is the viewpoint from which we formulate statements concerning that diversity. Thus you can say that in the world of sport there are differences concerning the bodily shape within

\footnotetext{
${ }^{1}$ The text has been written as a part of the research program BW. I. 43 - "Aesthetic aspects of sport" financed by the Polish Ministry of Science and Higher Education.
} 
particular sports as well as between different sports. An example of the first situation can be provided by men's running competitions. There we are dealing with heavily built sprinters and "ethereal" longdistance runners. To illustrate the second situation we can highlight a "binary" opposition between the bodies of basketball players and the jockeys. From the anthropological viewpoint we would have here a precise illustration of somatic differences resulting from different bodily build. The aesthetic viewpoint stops at shapes of those bodies and a conclusion concerning the extreme differences between them based on numerous variables: height, weight, colour of skin. That contrast, which is natural taking into account different characters of the abovementioned sports, loses its spectacular character when we refer to extreme forms of bodies in both sports. The tallest jockey of the world was Bruce Hobbs, who was $190 \mathrm{~cm}$ tall, which would provide him with a good position on a basketball court, while the shortest basketball player was Tyrone Curtis, who was $160 \mathrm{~cm}$ high, and hence in a good position for horse racing competitions.

Extremely different bodily forms are not synonymous with ideal forms of sports corporeality. When the subject of our research is the world of sport, which is composed of about 84 (Olympic) sports, we see the whole range of bodily shapes offered to us by nature. This enables bodily forms of differentiated appearance and various somatic features determining definite kinds of sports activity to come into being. Bodies which from the aesthetical viewpoint are similar to each other may have different somatic features predestining them for different forms of sport activity. The connection between somatic features and practised sports does not mean that the latter simply results from the first. It is impossible to construct a simple syllogism pointing out that definite sports activity results from having definite features. Admittedly, there exist definite somatic features which, according to common sense, predestine us for practising certain sports.

Patterns of sport corporeality are imbued in the world of Mediterranean culture through the bodily shapes coming from Greek sculpture, which survived in Roman copies reflecting changing fashions concerning the bodily shape which were present in the culture of ancient Rome. However, sources of those images of sports corporeality do not come from the real world of sport, but from its artistic creation, from sculptural realizations. Evolutionary strategies of nature bring about great diversity of forms of human corporeality. Such abundance of forms makes it possible to create differentiated forms of sporting competition, where the abovementioned forms of corporeality find their proper place in socio-cultural space. Some forms of the body even impose the way of life and professional career realized in the world of sport. This applies to both women and men. It is clearly visible in the case of women and men who are exceptionally tall. Basketball becomes for them the rationale for their bodily shape.

Patterns of bodily beauty should be patterns included in our everyday life. And the exceptional is something rare there; something which - thanks to that characteristic - becomes visible. The abovementioned patterns should also be connected with obtainable properties of our corporeality. You can do much with the shape of your body, but you can not lengthen or shorten it. The natural index for longitudal features is constant on the natural level. Referring to everyday life, this is visible in numerous rankings made up by the mass media and Internet surfers and concerning visual attractiveness of figures from the world of sport. Attractiveness in this context means not something different, strange, unparalleled, surprising, but something close to commonly accepted patterns of corporeality and bodily beauty, because the subject of evaluation is not the very shape of the body, but a combination of body sculpture and beauty of the face. Bodies characterized by types of beauty which suit patterns of visual attractiveness being in force in a given culture are "selected" from the world of sport. In the American /stereotypical, Californian/ version such an ideal pattern could be a sports "Barbie Doll" - a combination of bodily perfection, an ideally shaped body, with the Californian type 
of beauty. Anna Kournikova's permanent presence on various lists of the most attractive /top sexy, most beautiful/ women athletes seems to confirm this. Her figure unites both the abovementioned pictures of corporeality. Her body is not a picture of musculature, as is suggested by the bodies of female athletes in many track and field sports. While creating her own image Kournikova skilfully moves between the area of sport on the one hand, and popular culture and the world of advertising on the other. She is a model example of a figure from the world of sport who owes her success not to sports successes but to a skilfully constructed image.

Greek culture, while constructing the shape of the human body, found its ideal harmony in figures of Greek athletes, who spark today's imaginations about track and field athletes. The Greek athletic body is, as a matter of fact, a track and field body. The image of the body expressed by sculptures depicting Hercules is a "supernatural" form, it does not concern the human body and, in spite of the fact that it emanates power, it did not become a pattern of sports corporeality. Perfection was perceived in the male body of average somatic features but "sculptured" with movement, Hercules's form of the body was an exaggeration, excessive literalism in suggesting power. It was rather a mythical than an athletic body, rather a demigod's than a human body. And nobly born Greek warriors rather made themselves similar to an athletic than to a mythical body.

The feeling of bodily harmony is found in the male track and field body, although it is the form of the body which may be found in the majority of contemporary sports. It is a classic example of a cultural pattern. Its clearness is connected with belonging to the tradition of Mediterranean culture. A "grotesque" sumo wrestling contestant's body expresses different cultural traditions and patterns, which need not treat our perception of bodily harmony as something binding. Thus, aesthetical considerations on the shape of sports corporeality are cultural considerations. Identity-related character of such reflection on sport is manifested in evaluations of shapes of the body considered from the viewpoint of its visual attractiveness. Cultural differences are the source of different bodily patterns also considering the athletic body. Diversity of bodily forms in the area of sport is covered by specialization within particular sports. Fans are accustomed to particular forms of corporeality constituting the basis for sports competition in a given sport, they regard them as natural and proper. If they constitute an important element of sports competition - as happens in sports acrobatics or in weightlifting - they are not regarded as strange or curious.

The fact that differences in bodily shapes are natural within a given sport make them invisible. Only removing them from the context of sports rivalry and confronting them with other bodily forms makes them symptoms of difference. Such comparisons are, as a matter of fact, medial moves. They are manifestations of looking for visual attractions, forms attracting viewers' attention, in the world of sport. This is not far removed from one of the genealogical sources of contemporary sport constituted by marketplace-circus shows. Although the very world of sport does not create such an event as a display of bodily curiosities, such a product is potentially included in it and is occasionally highlighted by the mass media. Bodily curiosities are a natural subject of human interest. The largest, the smallest, the heaviest, the strongest become medial figures in some a priori way. They are given that status by "attractiveness of a curiosity" which does not require creative and marketing endeavours, which makes their corporeality different from the corporeality reflecting the level of the socially average bodily form, which requires creation by being given a cultural marker of perfection enabling a choice to be made.

Considerations on sports corporeality necessarily lead to a question about the archetype of the athletic body. It may be posed in a definite cultural tradition, which is constituted for us by traditions of Mediterranean culture evolving towards the contemporary form of Western culture. The subject of the analysis may be constituted here by the visual layer of culture enabling to the highlighting of 
patterns of bodily shapes through which the form of the athletic body used to be expressed. Attractiveness of a definite pattern of corporeality, its cultural popularity providing it with a semantic layer, may prove that it is perceived as a pattern of the athletic body. The visual layer of culture in the case of the subject we are interested in refers to figurative art. First images of the athletic body may be legitimately pointed out in the context of ancient Greek culture. A unique place of sports rivalry in Greek society made sport a subject of artistic studies of the shape of the human body and one of the subjects of sculpture and painting. Vase-painting primarily shows acts of sports rivalry. Sculpture, on the other hand, is focused on creation of the "sports portrait" constituting one of the elements of the prize for victory in sports games. What seems common for both branches of art is the search for an artistic form to create an image of the body.

Due to an incomplete picture of the surviving cultural artifacts of that time it is not easy to make a judgment for the sport model of the body to function in contemporary culture. Identifying the form of the body which we consider as defining the sport body in ancient Greece is a reflection made from the perspective of modern ideas and designs that we can indicate corporeality in contemporary sport. From this perspective, we can show four forms which could serve as a defining model of the sporting body in ancient culture and which we can identify with bodies in an example of sports in contemporary culture. Three of these relate to male bodies and one to female. One of them came into being as a result of looking for the canon of the human bodily beauty which was related to the athletic body as to the subject of its studies. Just that body was the place where ideal proportions, harmony and symmetry - expressed by Poliyclitus in his sculpture of Doryphoros - were found. Polyclitus's male nude is something like a synthesis of studies of the athletic body. Its prototype was a male nude carrying a spear - an attribute of sports rivalry - which gave it a clearly sporting pose. Polyclitus's "Doryphoros", regarded in the context of the history of sculpture, is an example of an archetypical male nude. Contemporarily, in spite of its mediation by the world of sport, it is not perceived as an image of an athletic body. Thus it cannot constitute an archetype of the athletic body, in spite of the fact that it has features of an athletic body. This refers especially to its typically athletic musculature. The way of emphasising it enables us to describe Polyclitus's nude as an athletic type. Classical for the male nude type in history of European sculpture is Polyclitus's "Diadumenos". Today the shape of the "Diadumenos" body, taken from the place where he stood, stripped of the attributes of sport, with an enigmatic positioning of the hands which does not define that body as a sporting body in an obvious manner. Its structure suggests that the body is smooth and formed as a result of physical activity. Bronze copies of this statue complete the form of the best known "Diadumenos" marble body. The positioning of the hands of the bronze copies show us a man tying up the band on his hair, which we define like a sporting gesture, and the body of "Diadumenos" like a possible pattern of the sporting body.

The role of an archetype of the athletic body understood as an archetypical cultural symbol seems to be played by the other form of sports corporeality created by Greek art. It was Myron's "Discobolus", the best known form of the athletic body from the time of ancient Greece, which became the pattern of the athletic body. Even the positioning of the body leads us to consider it as a sporting body. His athletic tendency is seen clearly. Regarding the bodily shape, it is not significantly different from Polyclitus's athletic type, indeed it is even a slightly more delicate form taking into account the way of emphasizing musculature, but it is simultaneously characteristic enough to be recognized as an athletic body. Myron's sculpture includes an unambiguous designatum which makes it possible to place the sculpture in the world of sport. This is the pose in which the male nude was presented - the pose reflecting a phase of an athletic movement - discus-throwing. 
The subject of Myron's sculpture is the body in movement. He presented "Discobolus" in a dynamic bodily turn, a moment before throwing a discus, which is a pose characteristic for the world of sport. The "sporty" character of "Discobolus"'s body is determined by the form of the movement in which it was presented. It is definitely a foreground element and simultaneously the one determining the sporty character of the Myron's sculpture. Myron's "Discobolus" has become one of the most recognizable ancient Greek sculptures, a symbol of its Olympic ethos, an expression of sports antiquity. In the contemporary Olympic movement it plays the role of an identity symbol pointing to the roots of contemporary Olympism.

Diversity of forms of sports corporeality in the contemporary world of sport makes recognition of only one form of the body as the archetype of the athletic body something problematic. However, it is possible to recognize the body expressing athletic movement as the archetypical one. In some sense what becomes archetypal is the very form of movement and the body becomes a background element, an object expressing movement. Thus it should be recognized that the archetype of the athletic body is the body in athletic movement. From that viewpoint, the "Discobolus" excellently fits such a role. What determines the "sporty" character is movement of the body and not its build. The archetypal character of the body of Myron's "Discobolus" is a consequence of recognizing that sculpture as an archetype of athletic movement. Polyclitus's "Doryphoros" - devoid of athletic movement - in spite of its sports genealogy is only an archetype of the male nude in sculpture. The very athletic movement, however, cannot determine sports corporeality. The form of the body must be harmonized with the form of athletic movement it is to represent.

The shape of the bodily form of "Discobolus" belongs to average forms of the athletic body. Thus the basis of the archetype of the athletic body is a form which is placed - in an Aristotelian way - between bodily extremities. It is not an image of force and power of the human body - which might be constituted by the "Farnese Hercules". Thus, not an expression of power but the form of movement determines the sporty character of the bodily image.

The third of the male forms is the embodiment of strength, power and extraordinary possibilities of the body and all it epitomizes in the Lysippus sculpture "Farnese Hercules". The person of Hercules in ancient Greece had a lot of sculpture and painting visualization. On the Olympic sport area there were lot of representation of Hercules' works and actions. Greeks athletes with "Herculean" corporeality try to follow his actions. Pauzanias once described such a person. It was Polydamos, the strongest man in ancient Greece, as was inscribed on the pedestal of his statue in the Olympic area, who killed a lion on Mount Olympus, like Hercules in Nemeia. The pattern of Hercules' body is present in the area of contemporary pop-culture, in cartoon and feature films, in the ideas of corporeality of wrestling, fitness and body building.

In the notion of the archetype of the athletic body the image of the male body predominates. However, it does not seem to exhaust the content of the notion. Hence a question about the archetype of the female athletic body should be posed. Masculine dominance in ancient sport seems to point to $20^{\text {th }}$ century sport as a cultural space where archetypical patterns of the female athletic body could appear. Such a role could be played by one of the female figures of the world of sport falling into the pattern of sports "Barbie Doll", although probably post-modern cultural diversity would mean that we would have to deal with a greater number of such figures and varied patterns. However, historical research makes it possible to point out a definitely more unambiguous and significant cultural pattern of the female athletic body which can be found in ancient times, although the fact that in the Renaissance and Baroque periods it was connected with the mythological space and the character of Diana deprived it of a significant sports context. 
Such a cultural pattern can be constituted by the mythical character of Atalanta. Atalanta was a significant pattern in ancient Greek culture referring to female social roles. Differences concerning the range of acceptable female social roles are visible in the cases of Ionian, Spartan and Athenian culture. The sporting model for the female body is the mythical figure of Atalanta which can be seen on preserved Greek vase paintings. There is a presumption that there were two myths of Atalanta: one is of the heroic valiant Grecian as the only women who took part in the expedition of the Argonauts and who was hunting with Meleagro for caledonian boar; the second shows the feminine nature, revealed by her neglecting the rivalry in a race by collecting the golden apples, thrown by Hypomenes during the famous race. The ancient Greeks saw the power of femininity in Atalanta preserved in European culture in the form of Diana. Atalanta in her Greek ethos is a character of a female who has not been beaten by males. Preserved Greek vases from the black-figure and red-figure period show Atalanta in the context of sports rivalry. Atalanta was unbeaten in running and wrestling and these are the sports activities which she is shown engaged in.

Such a pattern of sports rivalry can be pointed out in Spartan society, where women were allowed to compete with men, but vase paintings showing Atalanta also come from extremely conservative Athenian culture. Atalanta is shown running, preparing for wrestling, the wrestling fight against Peleus. Unlike the female figure taking part in games in Here's honour, she wears an untypical sportswear. She is virtually naked, she wears a hat covering her hair and sometimes a strange outfit resembling the $20^{\text {th }}$ century fitness outfits. Such sportswear we can find out in the III b.c. Roman mosaic in the Villa de Casale in Piazza Armerina. The character of Atalanta seems to play the role of a cultural pattern of a female character who is not submitted to male dominance, unbeaten in sports rivalry. In that context it is a significant archetype of the female sports character. Regarding her mythological genealogy her images are characterized by latitude. Maybe she is not so much an archetype of the sports female body as an archetype of femininity in the world of sport. From that viewpoint this may constitute one of the first gender patterns. European art views her as a model of feminine temptation, however the art of the Greeks clearly shows her athletic qualities. $17^{\text {th }}$ century paintings show Atalanta hunting with Meleagro, like in Rubens' "Atalanta and Meleagro", or collecting golden apples during the race with Hyppomenes, like in Guido Reni's "Atalanta and Hyppomenes" and many other paintings since the 14th century. The reinterpretation of the Atalanta gender pattern by Christian culture is a reflection of expressing masculinity in the subordination of femininity.

The body forms created by Polycleitus, Lysippus and Atalanta gave rise to many imitations within European culture. The most athletically accepted body - that shown in "Discobolus" by Myron - was repeated many times in sculptures, which themselves had little impact on body image in European art, although this physical structure can be found in the modern metrosexual body, e.g. David Beckham. Polycleitus's body remains an image of the athletic body which expresses strong male characteristics that meet the requirements of the social image of a "real" man used in advertising, drugs, films, actions, and numerous other forms of media depicting masculinity. Atalanta is a pattern of a fantasy and computer game heroes. The form of Hercules is referred to naturally by the entity of many athletic disciplines i.e. shot-put and discus, a modern Discobolus, and creating a culture around sports athletes.

Social and, especially, cultural placement of sports competition makes us use all possible forms of corporeality, corresponding with diverse sports post-fans' tastes, in its space. They constitute a picture of the sports body as the subject of sports competition and the object of its cultural transformations. 


\section{REFERENCES}

Bernhard, M. L. (1971). Sztuka grecka V wieku p.n.e. /Greek art in the V century b.c./. Warszawa: Wyd. PWN.

Clark, K. (1998). Akt. Studium idealnej formy /The Nude. A study in Ideal Form/. Warszawa: Wyd. WAiF i PWN.

Pauzaniasz (1968). Na olimpijskiej bieżni i w boju /Description of Greece/. Wrocław: Wyd. Ossolineum. 